\title{
Comparison of Three Methodologies for Quasi-2D River Flood Modeling with SWMM5
}

\section{John Beck}

ATB SA, Moutier, Switzerland.

\begin{abstract}
Three methods for quasi-2D model setup of a SWMM5 project are explored with the PCSWMM 5.6 software using real project data from a hydraulic study of the Birse River in the town of Court in Switzerland. The first method is the standard method for constructing a 1D-2D model with PCSWMM (quasi-2D mesh with direct connections towards the 1D conveyance network). Care needs to be taken in the model construction to avoid double accounting of the channel conveyance and overestimation of the channel roughness. The second method uses the technique of representing the river channel with a 1D approach and making orifice side connections with the quasi-2D floodplain mesh. Side connections can be tedious to construct, so a routine using FME software was developed to automatically create the orifice side connections. The third method uses a complete quasi-2D model to represent the river and floodplain conveyance. In this method, care needs to be taken in representing the bridges.
\end{abstract}

A 100 y return period flood is simulated for each PCSWMM model. The results of the three methodologies are compared. The advantages and disadvantages of each method are considered in terms of the time needed to construct the model and the time needed to process results. In the end, the SWMM5 quasi-2D river flood modeler will choose the modeling methodology according to the data and software available, and their proficiency with the available software.

\section{Introduction}

\subsection{Study Goals}

Quasi-2D hydraulic flood modeling was used $>45$ y ago by Zanobetti and Lorgeré (1968) to model the Mekong Delta. This quasi-2D model is described in detail in Cunge (1975). Metzger (2002) used quasi-2D modeling in the context of a geographical information system (GIS). Full two dimensional hydraulic models have been more frequently used in the last decade but these models often suffer from difficult model setup and the need to rely on simplifying assumptions or rating curves to model hydraulic structures. Often results processing is difficult due to the $2 \mathrm{D}$ nature of the results and investigating project alternatives is time consuming to implement.

The U.S. Environmental Protection Agency's Stormwater Management Model (SWMM 5.1) can be used as an integrated 1D-2D hydraulic model or as a complete quasi-2D hydraulic model. Third party software using the SWMM engine such as PCWMM, XPSWMM and InfoSWMM2D have developed integrated 1D-2D and 2D modeling procedures. Automatic mesh generation within these third party solutions is making 1D-2D integrated modeling and quasi-2D modeling more efficient and should allow for more frequent use of these models in hydraulic studies.
Computational Hydraulics International $(\mathrm{CHI})$ has developed PCSWMM 5.6, which is used in this study. Two PCSWMM 1D-2D modeling procedures are tested and a complete quasi-2D modeling procedure is also investigated. This testing is done to ensure that the three methods give similar results and to better understand the advantages and disadvantages of each methodology. Thus the goals of the study are to:

1. Explain the three methodologies and special steps used to prepare the data;

2. Compare the results with a historical flood to ensure the three methods produce reliable results; and

3. Explain the advantages and disadvantages of the three methods to help the SWMM user decide which method is the best to use in their case.

\subsection{Context}

The Birse River in Switzerland experienced significant flooding during the 2007-08-09 to 2007-08-11 flood event. In the town of Court, Switzerland many buildings were flooded by the Birse, including the wastewater treatment plant. ATB SA, a civil engineering consulting firm based in Moutier, Switzerland had already started a flood protection works study (in 2005) to improve protection against flooding and to restore as well as possible the biological functions of the river.

Beck, J. 2016. "Comparison of hree Methodologies for Quasi-2D River Flood Modeling with SWMM5." Journal of Water Management Modeling C402. doi:10.14796/JWMM.C402

(c) CHI 2016. www.chijournal.org ISSN 2292-6062. 
One dimensional hydraulic steady flow modeling was done with the U.S. Army Corps of Engineers' HEC-RAS for the entire reach of the Birse through Court and it was seen that the downstream reach in the town needed to be modeled with a 2D hydraulic model. Three methodologies for 2D modeling with PCSWMM 5.6 were investigated on this downstream reach of the Birse in Court, Switzerland.

\section{Study Area and Data}

\subsection{Study Area}

Figure 1 shows the significant watercourses and objects within the study area. The model area is within the red boundary.

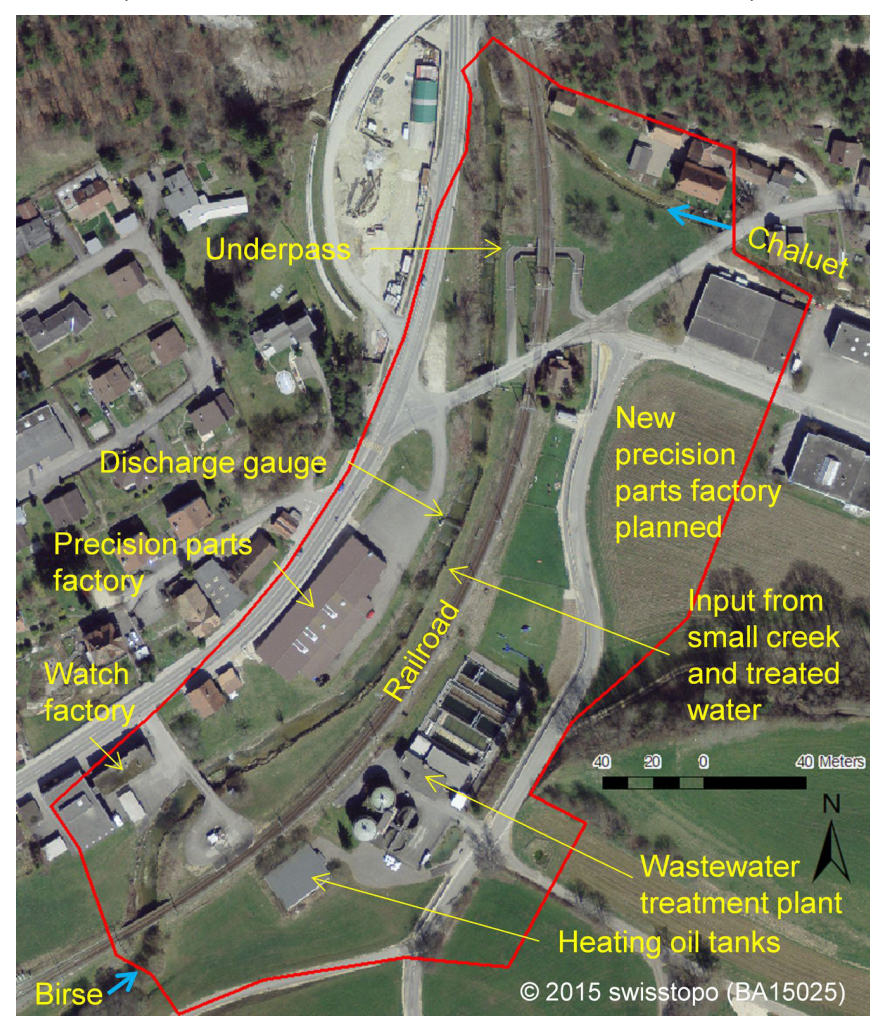

Figure 1 Model area, watercourses and significant objects.

\subsection{Data}

A significant amount of data, especially topographic data, is necessary for any 2D hydraulic model. This data is becoming more readily available with the large lidar topographic data sets available. This is the case in Switzerland with the SwissAlti3d data available for the majority of Switzerland (Swisstopo 2014). This data is helpful but not complete. Often the river bottom is missing as is much of the banks if they are woody. This data needs to be surveyed by total station surveying.

Topographic data for the study area is issued from three sources: ATB total station survey of the river; a digital terrain model (DTM) developed for the land reform project done in the framework of the A16 freeway project; and SwissAlti3d data
(Swisstopo 2014). This information was combined together in the Geomensura Genius software to create a triangulated irregular network (TIN) (Figure 2). This data was exported as Autocad 3D faces and converted to an Esri TIN in ArcGIS 9.3.1.

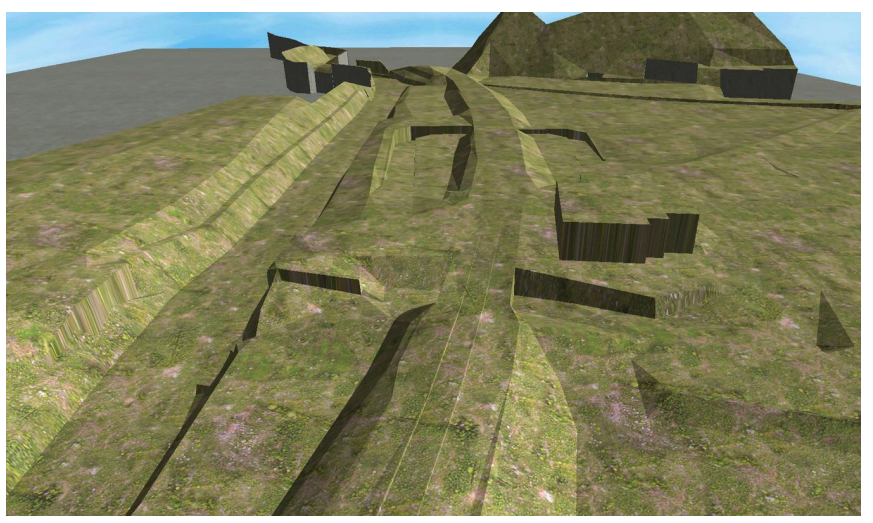

Figure 2 3D view of the TIN model created in Geomensura Genius.

One dimensional hydraulic steady flow simulations had already been done with HEC-RAS for the entire Birse reach through Court. The cross sections for those simulations were developed with HEC-GeoRAS (USACE 2015) with the same topographic data. Before starting the 2D modeling, the HEC-RAS 1D model was imported into PCSWMM (Figure 3). Finney et al. (2013) showed that accurate 1D unsteady modeling of imported HEC-RAS cross sections was feasible with PCSWMM.

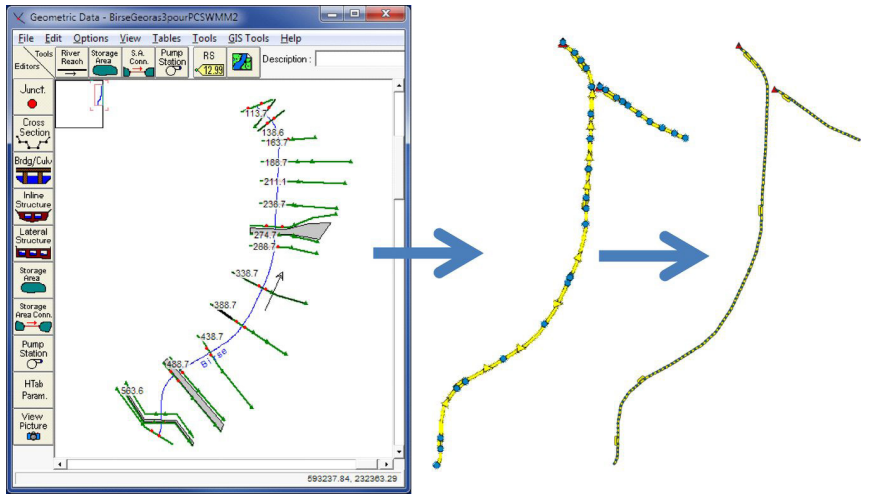

Figure 3 Importing HEC-RAS geometry into PCSWMM and then interpolating in PCSWMM.

It is recommended to do a test with PCSWMM comparing a within-channel flow with HEC-RAS results to be able to adjust singular losses at hydraulic structures, particularly bridges. When this comparison is satisfactory, the modeler can then develop the 2D mesh. Two dimensional model creation with PCSWMM is described on the support pages of the $\mathrm{CHI}$ Water web pages $(\mathrm{CHI}$ 2014b; CHI 2013).

The 2D model area is drawn in PCSWMM or in a GIS and opened in PCSWMM (see Figure 1 above for the 2D model area in this study). For 1D-2D integrated modeling the modeler then creates $2 \mathrm{D}$ nodes and can create $2 \mathrm{D}$ elevation points for developing 
the topographic definition. This option is used in this study to increase the topographic definition using the TIN available in ArcGIS. PCSWMM elevation points are opened in ArcGIS (Figure 4). Additional elevation points are added from 3D breaklines (levees and walls in this study area). These points are then given elevations via the ArcGIS 3D Analyst Surface Spot tool.

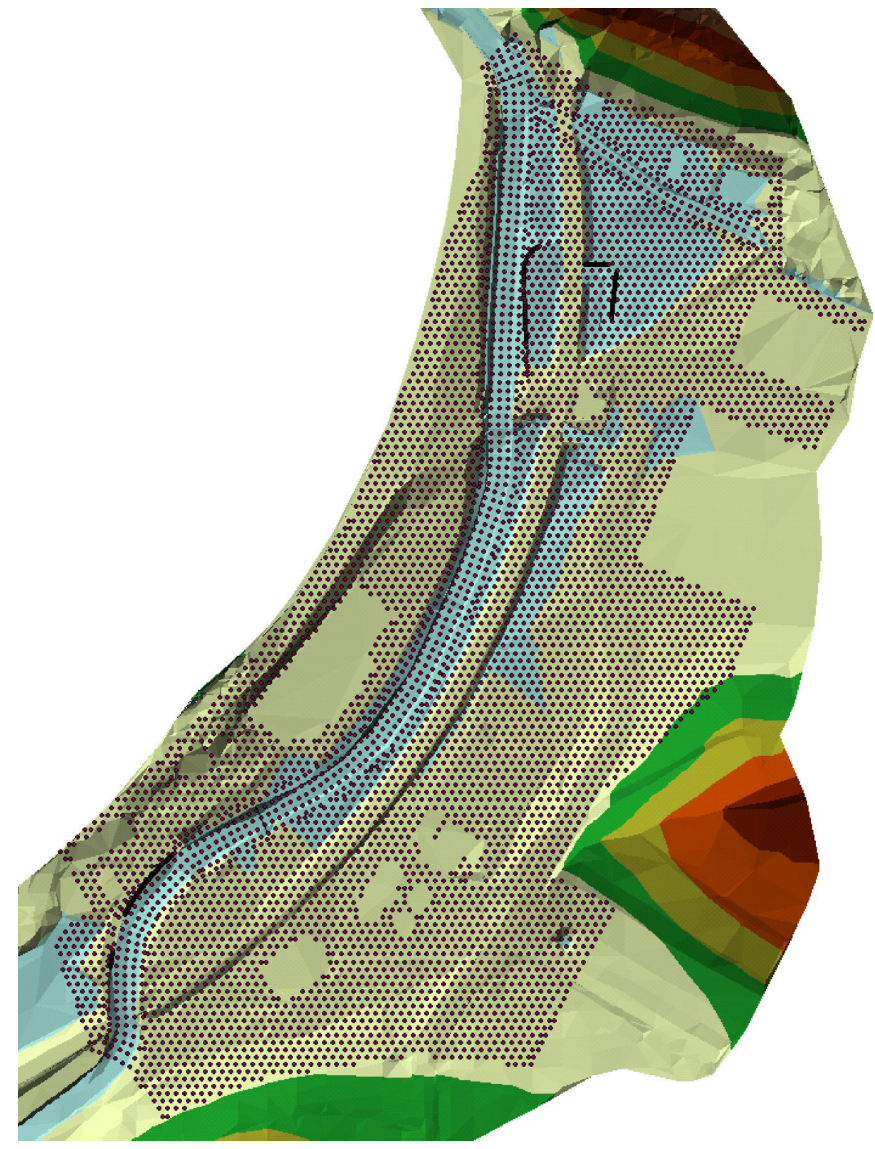

Figure 4 PCSWMM elevation points opened in ArcGIS to receive elevations from the ESRI TIN.

\section{Three Methodologies for Quasi-2D Modeling with SWMM5.1}

\subsection{D-2D Direct Connections}

Direct 1D-2D connections is the standard PCSWMM method of integrating a 1D channel network with a 2D floodplain (Figure 5 below). When dealing with a river network it is important to use direct connections and not the bottom orifice approach (CHI 2014c). The bottom orifice approach is used primarily for an urban setting when water flows in or out of the stormwater collection network onto or from the streets or ground.

In the direct connection approach, PCSWMM moves the closest 2D node and its associated conduits to the 1D channel node, deletes the 2D node and adds offsets from the 1D channel node to the 2D floodplain nodes. These offsets dictate when the floodplain will start to flood or when the 2D mesh that covers the channel will start to contribute to channel conveyance. Care needs to be taken in creating the 2D mesh that covers the channel because that mesh could add additional flow area, but will also add wetted perimeter if water flows onto it. Therefore, it is necessary to balance these competing conveyance factors when choosing the channel 2D mesh elevations and roughness.

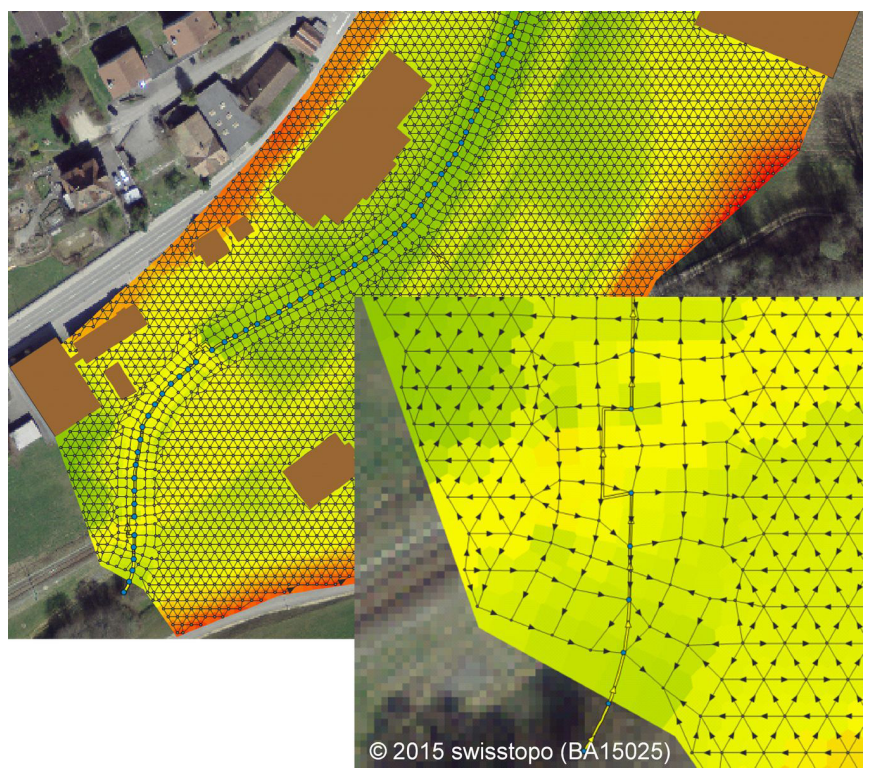

Figure 5 Direct connections between the 2D mesh (black lines) and 1D river channel (yellow lines).

\subsection{D-2D Side Orifice Connections}

The 1D-2D side orifice connection method is the second suggested method for 1D channel-2D floodplain modeling in PCSWMM (Figure 6).

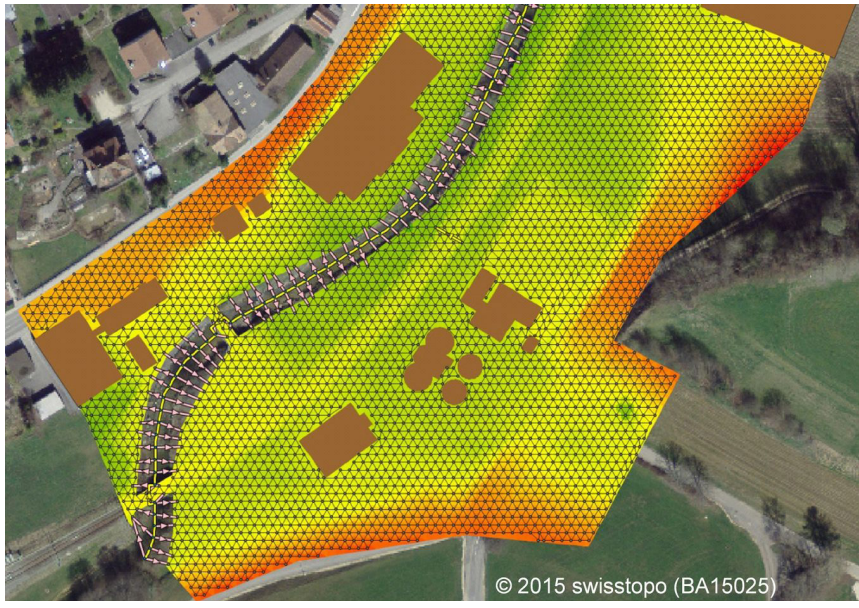

Figure 6 Side orifice connections (pink lines) between the 2D mesh (black lines) and 1D river channel (yellow lines).

Side orifices can be used in SWMM5 to represent the flow interaction between the main channel and the floodplain. Although the side orifice element is used, it will act as a weir until the orifice becomes pressurized. Thus the side orifice approach 
will be a side weir approach if the orifice height is sufficient. The hydraulics behind this method are more straightforward as there is no issue with double conveyance or increased wetted perimeter of the channel due to overlying 2D mesh conduits.

Making the side orifice connections is a relatively manual procedure if done within PCSWMM (CHI 2014c). To automate the procedure, a routine was created within Safe Software's FME. FME is used for numerical data conversion and transformation. It can read hundreds of data formats, transform the data and then write it to any of those supported data formats.

PCSWMM creates Esri shape files for the spatial data of a SWMM input file. This increases the data processing possibilites via other GIS software. The shape files for the junctions, outfalls, and conduits are read into FME. FME transformers are then used to process the data and do the calculations according to the workflow shown in Figure 7. The workflow is done for right and left banks separately. If orifice side connections are needed for more than one river, the FME routine is repeated one river at a time. The SideConnectionData shape file is then imported into PCSWMM.

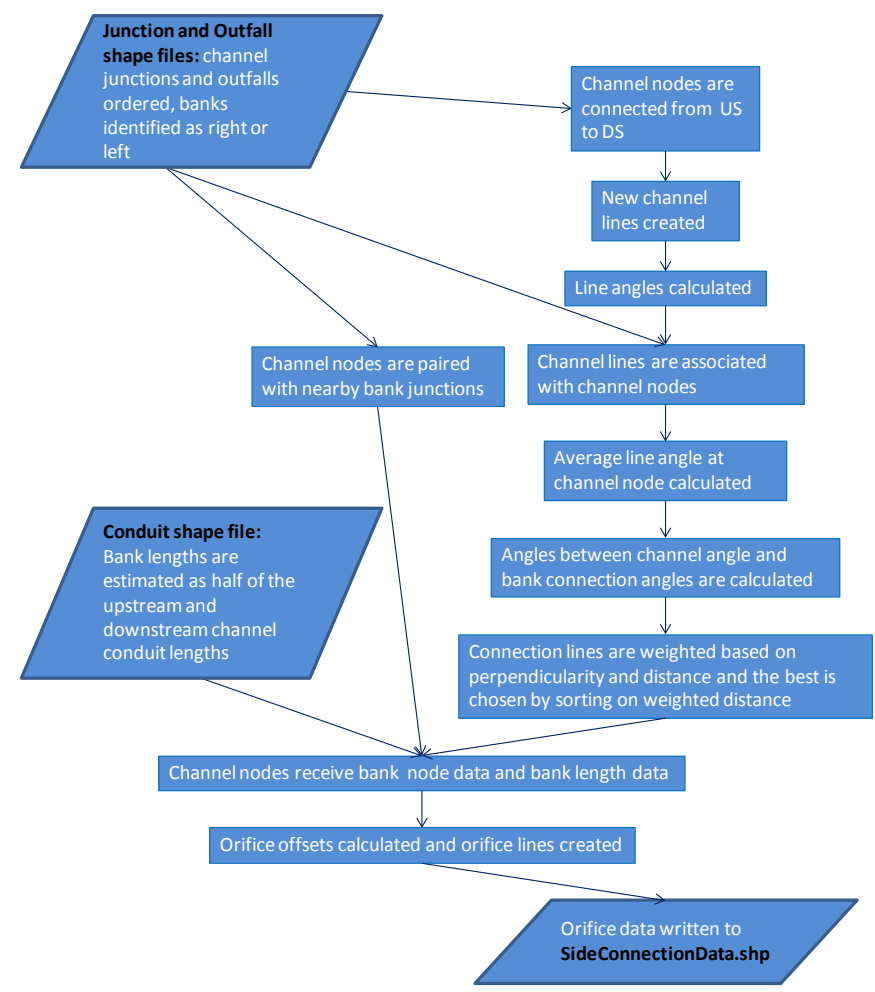

Figure 7 FME workflow for creating orifice side connections from PCSWMM junction, outfall and conduit shape files.

\subsection{Full Quasi-2D}

Quasi-2D simulations with PCSWMM have been benchmarked (James et al. 2013) against other 2D models. The excellent benchmark results and the new SWMM5.1 option to be able to use a no-wall rectangular conduit promotes a third method for quasi-2D modeling: full quasi-2D. In this method, the channel is represented entirely by a $2 \mathrm{D}$ mesh. The channel wetted perimeter needs to be modeled with appropriate elements, and bridge conveyance areas (above or below deck areas) need to be added to the 2D mesh generated by PCSWMM.

The first special consideration to make is how to represent the wetted channel perimeter. If only one channel streamline is used, then it can be represented by a two walled open rectangular conduit. If multiple streamlines represent the channel area, then bank streamlines should probably be set to one-wall open rectangular conduits while the centerlines are no-wall open rectangular conduits. Irregular conduits could be used, but in such a case, it would be better to use a 1D-2D approach rather than the full quasi-2D approach.

Secondly, the upper or lower bridge conveyance area needs to be added to the model. Three methods (Figure 8 ) for doing this are tested and the results are shown in Section 5. The first method consists of simply adding the single bridge conduit to the model. The second method also uses the same bridge conduit, but additional conduits bring flow from each upstream streamline to the bridge conduit and additional conduits distribute the bridge flow to the downstream 2D channel nodes. The third method consists of using multiple conduits to represent the bridge opening area or deck area. It is necessary that the sum of the multiple conduits' flow areas equals the single bridge conduits' flow area. The wetted perimeter can be approximated by using one- or two-wall open rectangular conduits or even a closed rectangular conduit. To better approximate the wetted perimeter when the bridge is pressurized, it might be necessary to add walls to the conduits in those simulations.

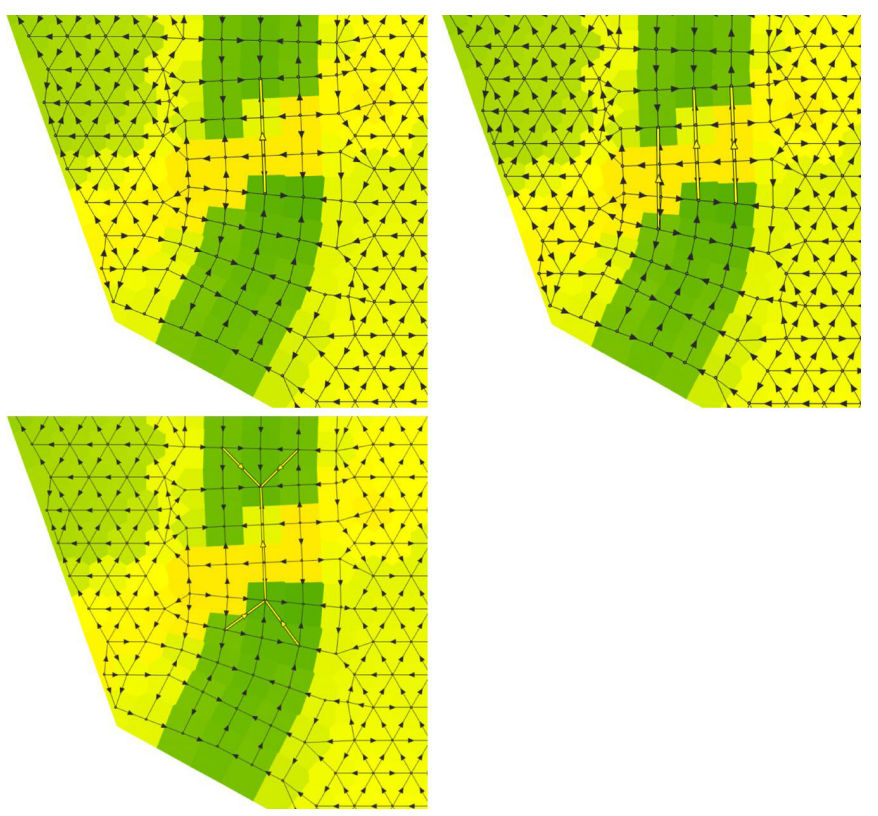

Figure 8 Methods for incorporating bridges into a full quasi2D PCSWMM mesh (bridge conduits are represented by yellow lines); upper left: single bridge conduit; lower left: improved single bridge conduit; upper right: multiple conduits. 


\section{Final Model Construction Steps}

Before simulations are run, it is necessary to finish the model construction. Roughness zones can be attributed to the mesh by using multiple mesh boundaries in PCSWMM. In the case of a single mesh, as in this study, it is also possible after the mesh creation to open the PCSWMM conduits shape file in a GIS and give roughness values to the conduits by spatial join procedures in the GIS.

The downstream boundary must be set. In this study, it is simply the outfall imported from the 1D HEC-RAS model.

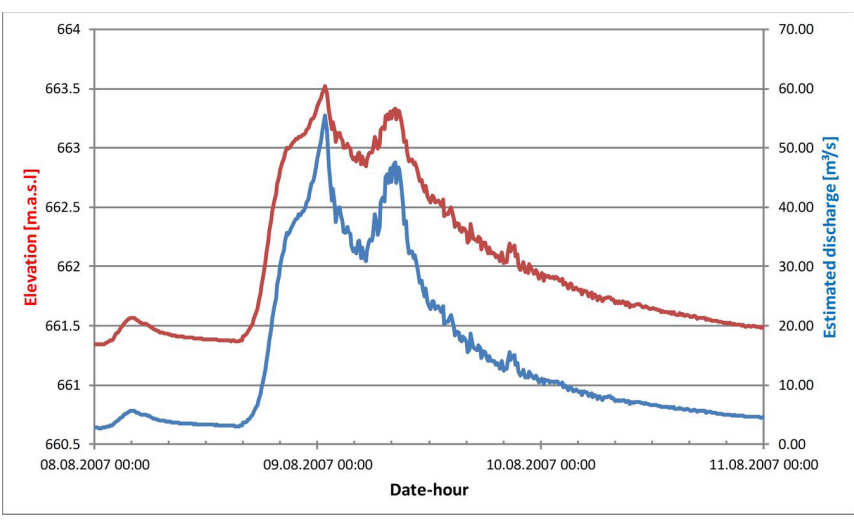

Figure 9 Birse River water level and estimated discharge time series measured at the Court gauging station (data courtesy of the Canton of Bern, Switzerland).

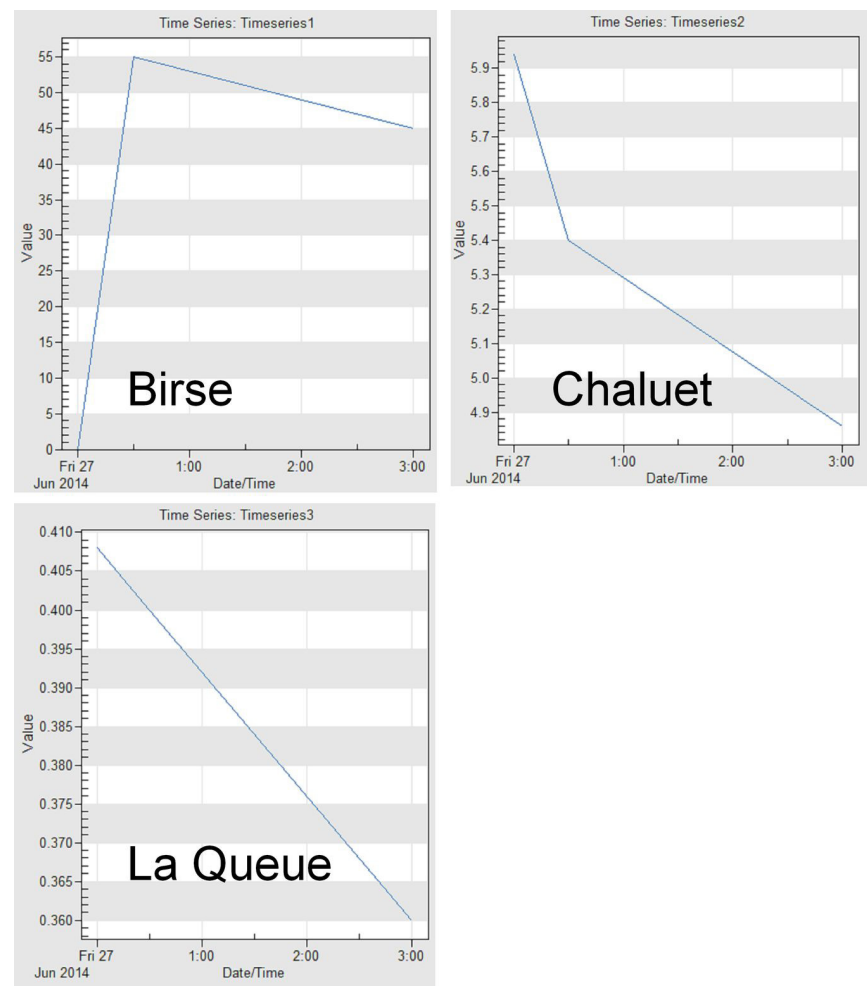

Figure 10 Simulated discharges for the Birse River, Chaluet Creek and La Queue Creek.
Finally the input discharges are prepared. A maximum discharge of $55 \mathrm{~m}^{3} / \mathrm{s}$ for the Birse River equivalent to the 2007-0809 to 2007-08-11 flood is simulated (Figure 9 above). Simulating the entire hydrograph would be inefficient so only a simplified version of the top of the hydrograph is simulated and tributary contributions are also estimated (Figure 10 above). It is assumed that the tributaries are already on their falling limbs when the simulation starts.

\section{Comparison of the Results of the Three Methods}

The hydrographs of the $100 \mathrm{y}$ return period Birse River flood (Figure 10 above) were simulated for each of the three methods and for each of the three bridge methods of the full quasi-2D method. The simulation time step was $0.25 \mathrm{~s}$ and inertial terms were ignored in the dynamic wave routing method.

The maximum depth map of each simulation follows and then comparisons are made between the three quasi-2D modeling methods and also between the bridge methods by examining the Birse longitudinal profile of the simulated water surface elevations.

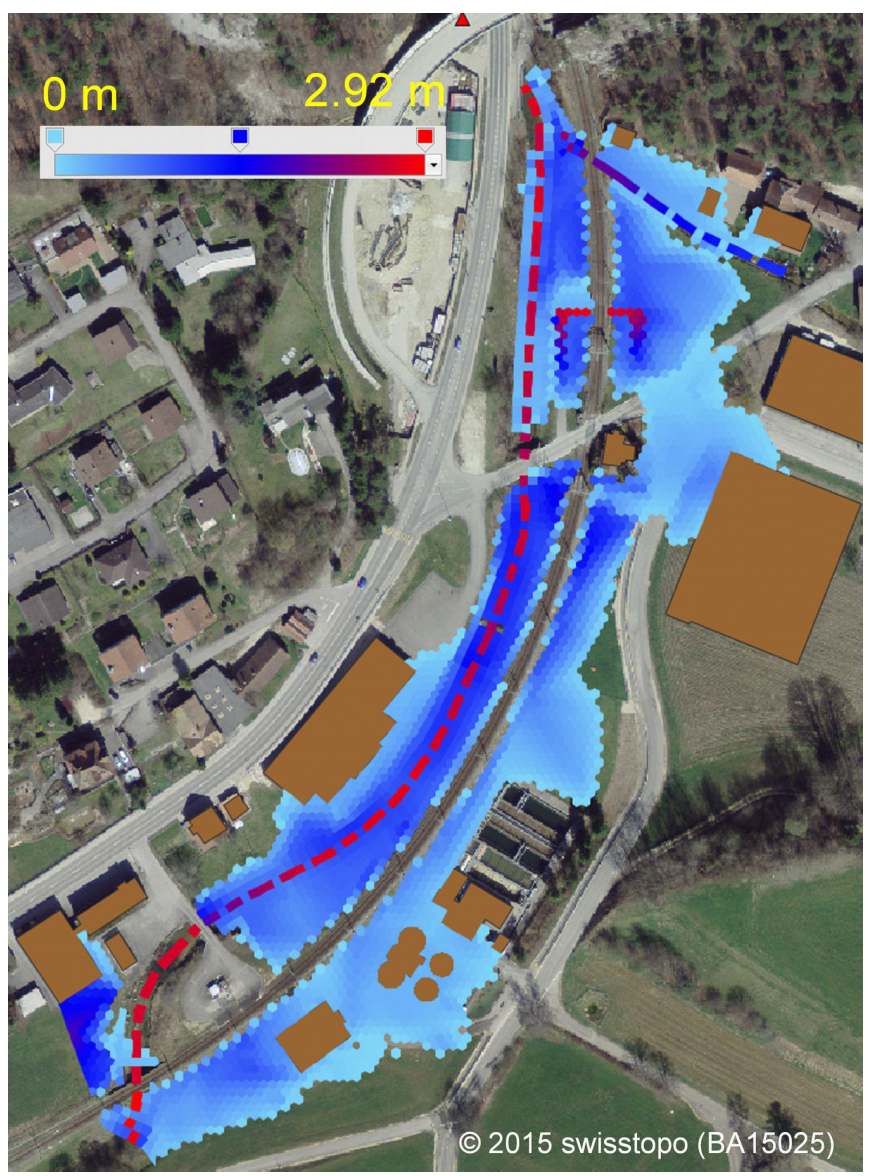

Figure 11 Maximum depth map of the 1D-2D direct connection simulation. 


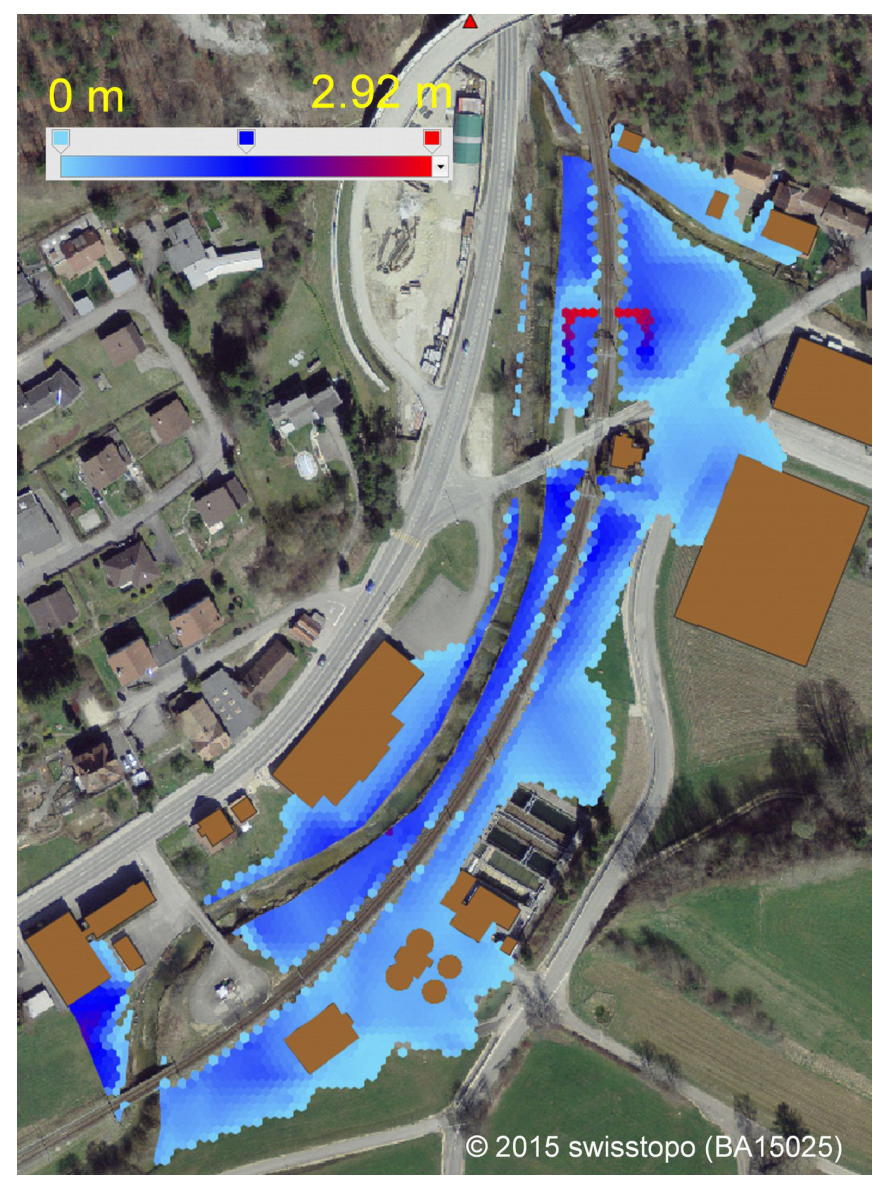

Figure 12 Maximum depth map of the 1D-2D side orifice connection simulation.

\subsection{Comparison of Maximum Depth Maps}

Figures 11 above, 12 above and 13 above show the maximum depth maps with the same gradient scale of $0 \mathrm{~m}$ to $2.92 \mathrm{~m}$ for the direct connection, side orifice connection, and full quasi-2D methods respectively. The spatial extent is very similar among the three simulations and it will be seen in the following section that the channel depths are very similar also. The intermingled high and low depths along the channel centerlines in Figure 11 result from a few of the channel $2 \mathrm{D}$ cells not being directly connected to the 1D channel. This does not have an effect on the results. The 1D-2D methods have a slight visual disadvantage compared to the full quasi-2D maps because the channel water depths are not represented (side-orifice method) or only partially represented (direct connection method). It is possible to overcome this by combining the 1D and 2D junction results in a GIS but this would demand additional work.

\subsection{Longitudinal Profile Results}

Firstly, it was necessary to test a few methods for treating bridges in the full quasi-2D method. Those methods are described in the

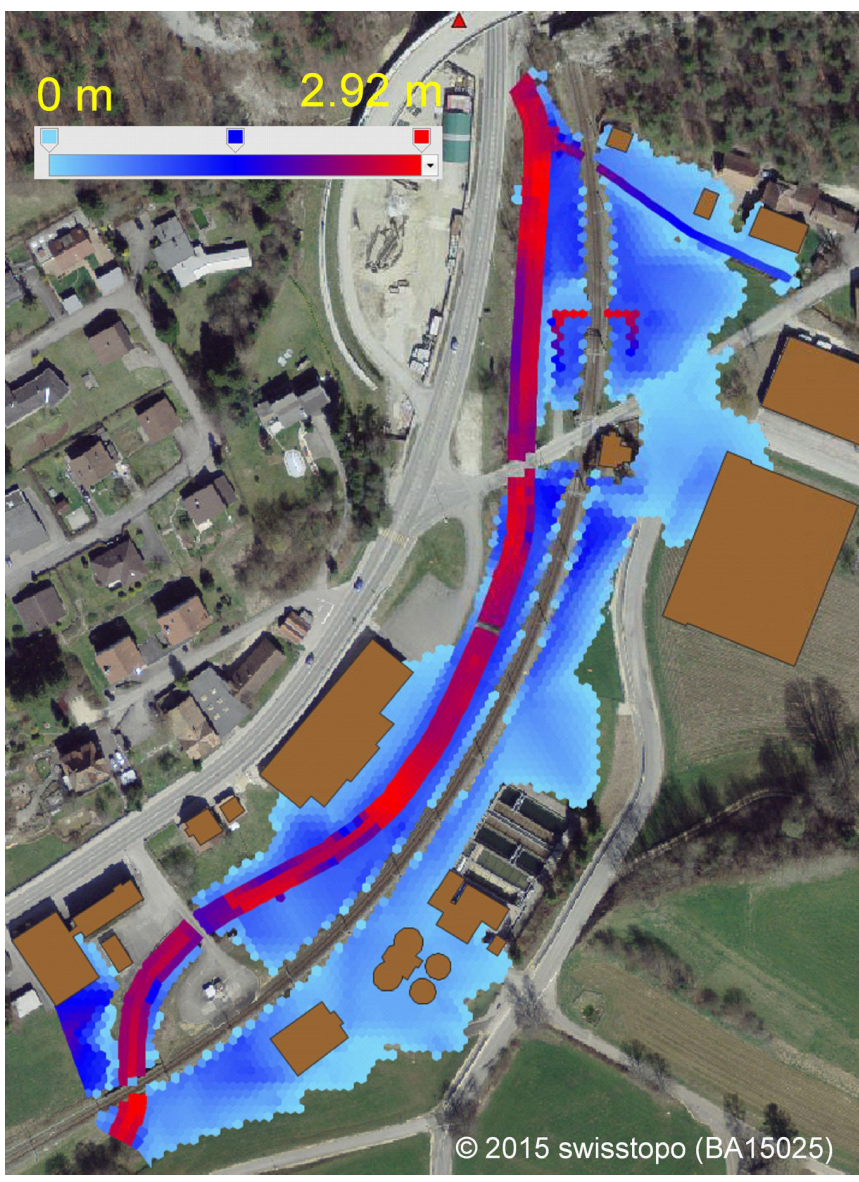

Figure 13 Maximum depth map of the full quasi-2D simulation using the improved single bridge method.

previous section and the $100 \mathrm{y}$ simulation results are shown in Figure 14. It can be seen that the majority of the simulated water surface elevations (WSEs) are within a few centimeters and that all are within $10 \mathrm{~cm}$. The multiple conduits method gave some higher and lower WSEs compared to the others. This is understandable because open rectangular and closed rectangular conduits were used to approximate the flow area and wetted perimeter. To be more precise, custom conduits would have been necessary, although these would have taken more time to develop. The single bridge conduit method gave slightly higher results. This is understandable because additional head loss will occur moving water from the bank streamlines toward the single bridge conduit. To improve this situation additional conduits were added upstream and downstream (Figure 8 above) to allow water flow to and from the single bridge conduit with less head loss. The improved single bridge conduit method seems to be the best compromise for a fast and accurate way of implementing bridge open areas in a full quasi-2D simulation. 


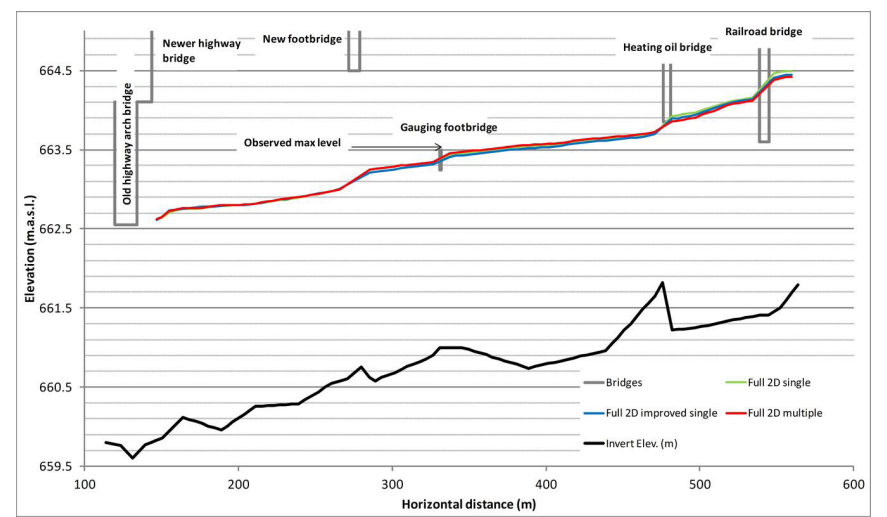

Figure 14 Longitudinal profile of the Birse water surface elevation results of the three full quasi-2D bridge methods.

The longitudinal profile water surface elevation results for the three quasi-2D methods are shown in Figure 15. Again the majority of the results are within $5 \mathrm{~cm}$ and all within $10 \mathrm{~cm}$. The three methods give a result within $10 \mathrm{~cm}$ of the observed level. Branch debris was caught on the gauging footbridge which certainly caused the measured levels to be higher than the simulated ones. Since the quantity of debris was unknown, the obstruction was not simulated.

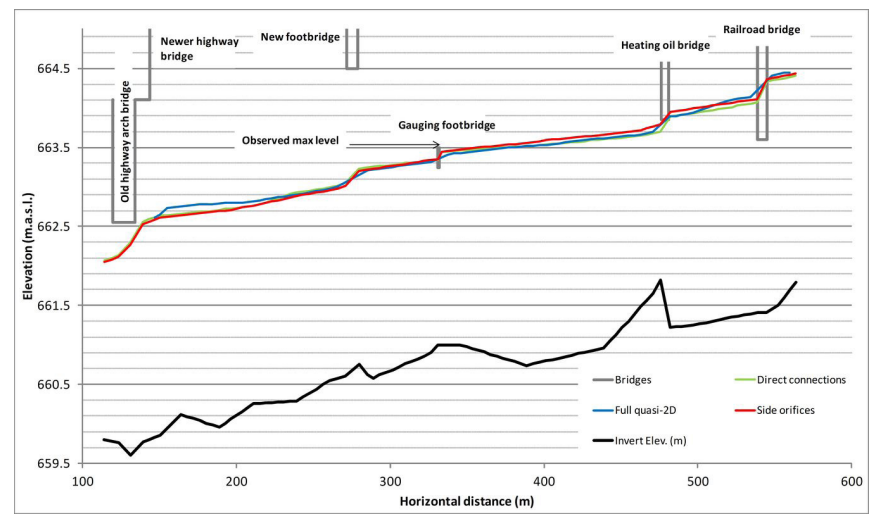

Figure 15 Longitudinal profile of the Birse water surface elevation results of the three quasi-2D modeling methods.

The largest difference in the results occurred roughly at a horizontal distance of $150 \mathrm{~m}$. This occurred due to geometrical differences and not due to the method. The full quasi-2D mesh better captured the bed topography compared to the 1D cross sections. It is assumed the full quasi-2D result is better in this part of the reach. In other parts, the full quasi-2D method does not necessarily follow the same tendency as the other two methods. It is again assumed that the improved topographical representation is responsible for this. Upstream from the gauging footbridge, it can be seen that the direct connections method tends to give slightly lower water surface elevations than the side orifice connections method. In this part of the reach, especially between the gauging footbridge and the heating oil bridge, the increased conveyance was not counterbalanced enough by the increased wetted perimeter and the results are probably a few centimeters too low. Without very detailed observations, it is impossible to tell which method is better. The results are very similar and are quite usable for river flood analysis.

\section{Discussion}

Benchmarking of the full quasi-2D modeling has already proved that SWMM quasi-2D modeling performs well compared to other 2D models (James et al. 2013), including 2D models solving the depth integrated Navier-Stokes equations. The following discussion serves the modeler in understanding the implications of three different quasi-2D modeling procedures for producing fast quasi-2D modeling results for river flood studies.

Table 1 presents the advantages and disadvantages of each of the three quasi-2D modeling procedures.

Table 1 Advantages and disadvantages of each of the quasi2D modeling methods.

\begin{tabular}{|c|c|c|c|c|}
\hline Method & $\begin{array}{c}\text { Third Party } \\
\text { Software }\end{array}$ & $\begin{array}{l}\text { Data Preparation } \\
\text { Difficulties }\end{array}$ & Simulations & Project Alternatives \\
\hline $\begin{array}{l}\text { Direct } \\
\text { connections }\end{array}$ & $\begin{array}{l}\text { Mensura, } \\
\text { ArcGIS, } \\
\text { PCSWMM }\end{array}$ & $\begin{array}{l}\text { Fill channel in DTM; } \\
\text { Prepare } 1 D \text { irregular cross } \\
\text { sections to avoid surcharge } \\
\text { if necessary. }\end{array}$ & $\begin{array}{l}\text { Balance between increased } \\
\text { roughness and increased } \\
\text { conveyance with } 2 D \text { channel } \\
\text { elements demands verification. }\end{array}$ & $\begin{array}{l}\text { New channel cross } \\
\text { sections easily } \\
\text { simulated. }\end{array}$ \\
\hline $\begin{array}{l}\text { Side orifice } \\
\text { connections }\end{array}$ & $\begin{array}{l}\text { Mensura, } \\
\text { ArcGIS, } \\
\text { FME, } \\
\text { PCSWMM. }\end{array}$ & $\begin{array}{l}\text { 2D zone without channel; } \\
\text { Manual orifice connections } \\
\text { time consuming, auto- } \\
\text { mated procedure with GIS } \\
\text { software is needed; } \\
\text { Prepare 1D irregular } \\
\text { cross sections to avoid } \\
\text { surcharge. }\end{array}$ & $\begin{array}{l}\text { Stability issues, often more } \\
\text { simulations needed to find a } \\
\text { stable solution. }\end{array}$ & $\begin{array}{l}\text { New channel cross } \\
\text { sections easily } \\
\text { simulated. }\end{array}$ \\
\hline Full quasi-2D & $\begin{array}{l}\text { Mensura, } \\
\text { ArcGIS, } \\
\text { PCSWMM }\end{array}$ & $\begin{array}{l}\text { DTM with channel is } \\
\text { necessary; } \\
\text { Use open rectangular no } \\
\text { walls option accordingly; } \\
\text { Add bridges manually. }\end{array}$ & Stable. & $\begin{array}{l}\text { New channel cross sec- } \\
\text { tions are more difficult } \\
\text { to test if an alternative } \\
\text { DTM is unavailable. }\end{array}$ \\
\hline
\end{tabular}

None of the third party software used in this study is absolutely necessary to be able to implement the three presented methodologies in SWMM5.1, although the automated procedures in PCSWMM 5.6 for mesh creation are significant time savers which would have to be replaced by other automated procedures for quasi-2D modeling to be feasible. It is worth noting that other third party solutions using the SWMM engine propose 1D-2D modeling approaches but they depend on other 2D models and do not automate quasi-2D mesh production. The production of a TIN can be done entirely within Esri ArcGIS or another GIS software so Geomensura Genuis is unnecessary although it tends to be faster for generating a TIN. A GIS software that can open the PCSWMM shape files is very helpful to complement the GIS capabilities of PCSWMM. For practical use of the side orifice connections method, it is necessary to automate the construction of the side orifices. A FME workbench was created to do this. The 
procedure is described in Figure 7 above. It could be reproduced in other software capable of automating the procedure.

In terms of data preparation, the direct connections and side orifice connections methods need a 1D channel representation. Using PCSWMM it is possible to import a HEC-RAS channel and for this study HEC-GeoRAS was used to create the geometry from the DTM for use in HEC-RAS. Of course, the 1D channel model could be created directly in SWMM5.1. It is important to only represent the channel and not the overbanks in the SWMM5.1 1D river representation.

Topographic data preparation is an essential part of 2D modeling (Metzger 2002). The model must have the topographic data resolution in coordination with the desired results. Topographic controls on the flow must be recognized and represented in the model.

It is recommended to use a filled-in channel DTM for the direct connections method. Doing this allows forces the user to make an initial reflection on the interaction between the $2 \mathrm{D}$ mesh and the 1D channel network. A PCSWMM support page proposes a workaround that bases the overlying channel 2D mesh points on nearby overbank points (CHI 2014a). Creating a filled-in channel can be cumbersome depending on the GIS software and topographic data available which can make the direct connections method somewhat difficult to implement. The PCSWMM workaround is quite helpful. Verification is necessary regardless of the procedure and some adjustments to the 1D-2D conduit offsets might be necessary to ensure flooding onto the 2D mesh occurs at the correct elevation.

No special DTM treatment is necessary for the side orifice connections method. This can be a significant advantage when the 1D channel is properly represented by cross sections and the DTM channel representation is poor.

For the full quasi-2D method, the channel topography needs to be integrated into the DTM. This is best done with GIS software that can create a TIN. Channel beds most often need to be surveyed by total station surveying or bathymetric sounding and then integrated into a high resolution TIN. This can be prohibitive to using the full quasi-2D method.

Care needs to be taken in preparing the 1D channel for the direct connections and side orifice connections methods. In the 1D direct connections method, the user must decide if they allow the cross section to be surcharged. If the cross section is surcharged and the 2D channel mesh is rough with shallow flows, the resulting water surface elevations tend to be higher than normal because of the additional wetted perimeter. In this situation, it is advisable to adjust the SWMM transect to avoid surcharging (Figure 16). This adjustment is done by adding a fictive high cross section point. Contrarily, if the cross section is not surcharged and the $2 \mathrm{D}$ channel mesh flow is deep, the extra conveyance provided by the unrestricted transect can cause underestimated water surface elevations. In this case the fictive high point needs to be lowered or not implemented at all.

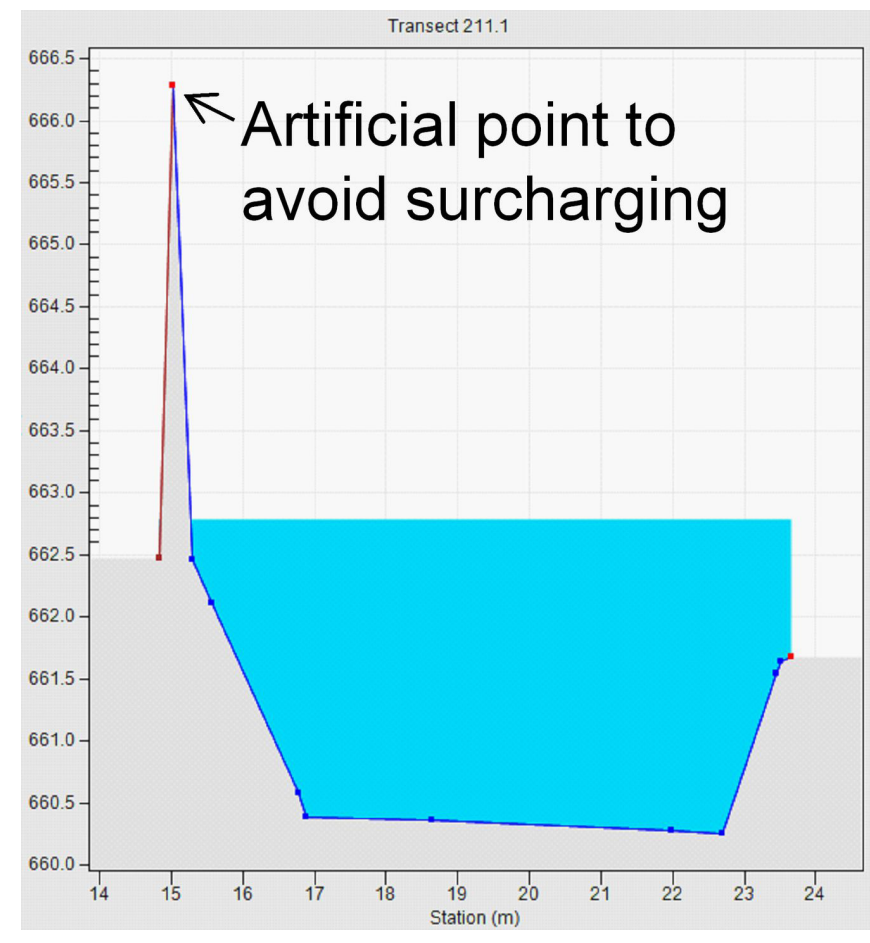

Figure 16 Adding high fictive points to SWMM transects to avoid surcharging open channels.

In the 1D side orifice connections method, it is important to avoid surcharging the 1D channel transects. The high fictive point should always be added to cross sections that would otherwise be surcharged.

Bridges need to be modeled properly in all three methods. If a HEC-RAS model is imported with the PCSWMM procedure, bridge conduits are created as custom conduits with shape curves. This automated procedure takes care to properly reproduce the flow area and wetted perimeter of the HEC-RAS bridge open area and high chords at all depths. If such an automated procedure is not used, the user needs to take care that the conduits correctly represent the flow area and wetted perimeter at all depths. Whenever dealing with hydraulic structures, it is important to be able to calibrate the model. This is done by adjusting the entrance, exit or average conduit losses. If the structure is a culvert, culvert codes are available in SWMM and they should be used to represent the head losses. For the full quasi-2D method with the availability of the single bridge conduits from HEC-RAS, the improved single bridge conduit was relatively fast to implement and seemed to alleviate additional head loss caused by the single bridge conduit method.

In terms of the number of simulations, the three methods can require more or less simulations depending on the modeled situation. For the direct connections method, it might be necessary to make several simulations before a final solution is acceptable due to adjustments that might need to be made to correct over- or underestimation of the water surface elevations due to channel conveyance and roughness issues as discussed above. The direct connections method tends to be quite stable. 
For the side orifice connections method, the simulations tend to be less stable during the rising limb when the orifice connections start to interact with the floodplain. To ensure that this is the cause of the model routing error, it is recommended to start a simulation from a hotstart file with the channel already flooded. It is also recommended to graph channel junction total inflows to verify for instability. These extra simulations and verifications for the side orifice connections tend to make it a little slower for generating a final solution.

The full quasi-2D method produces very stable simulations and tends to need the least number of simulations for producing a final solution.

Often 2D modeling is calibrated against an initial situation and then changed to simulate project alternatives. The project alternatives modeling needs to be taken into account when choosing the method to use. If the project alternatives are available as cross sections, those cross sections can be quickly incorporated as transects in the direct connections and side orifice connections method. The user does need to be careful in deciding if the $2 \mathrm{D}$ overbank mesh needs to be adjusted or not.

If the project alternatives have been incorporated into TINs, then the 2D mesh can be quickly adapted based on new elevation points.

\section{Conclusions}

Via a real case study for the 2007-08-09 to 2007-08-11 flood in Court, Switzerland three quasi-2D river flood modeling methods using PCSWMM and the SWMM 5.1 engine were tested. The results for all three methods are excellent compared to the observed 2007 flood extent and a measured water level. The advantages and disadvantages of each method were discussed. In summary, the following conclusions can be made:

- the topographic definition can be improved using a TIN within GIS software to update model elevations;

when an existing 1D HEC-RAS model is available, the 1D-2D with direct connections seems to be faster than the side orifices method for producing a good final solution; and

- if a DTM/TIN with the channel bed is available for the initial situation and for any project alternatives to be tested then the full quasi-2D method seems to be the fastest for producing a good final solution.

The results of this study should guide the SWMM5.1 river flood modeler in their choice of the best method to use. In the end, they will make their choice based on the data and software available and the results to be produced.

\section{Acknowledgments}

The Town of Court and the Canton of Bern are thanked for the land reform project and flood study project data which were made available for this applied research.

\section{References}

$\mathrm{CHI}$ (Computational Hydraulics International). 2013. Creating a PCSWMM 2D Model. Guelph: CHI Support. http://support.chiwater.com/support/solutions/articles/29927-creating-a-pcswmm-2d-model.

$\mathrm{CHI}$ (Computational Hydraulics International). 2014a. Avoiding double accounting of channel volume. Guelph: $\mathrm{CHI}$ Support. http://support.chiwater.com/support/solutions/articles/3000022928-avoiding-double-accounting-of-channel-volume.

$\mathrm{CHI}$ (Computational Hydraulics International). 2014b. Changes to 2D Modeling in PCSWMM Version 5. Guelph: CHI Support. http://support.chiwater.com/support/solutions/articles/3000017428-changes-to-2d-modeling-in-pcswmmversion-5-5.

$\mathrm{CHI}$ (Computational Hydraulics International). 2014c. Connecting a 1D Model to a 2D Overland Mesh. Guelph: CHI Support. http://support.chiwater.com/support/solutions/articles/179505-connecting-a-1d-model-to-a-2d-overlandmesh.

Cunge, J. A. 1975. "Two-dimensional Modeling of Flood Plains." Chap. 17 in Unsteady Flow in Open Channels, edited by $\mathrm{K}$ Yevjevich and V Mahmood, 3 vol. Fort Collins, CO: Water Resources Publications.

Finney, K., R. James, W. James and T. Xiao. 2013. “Efficiency and Accuracy of Importing HEC-RAS Datafiles into PCSWMM and SWMM5". Journal of Water Management Modeling 2013:R246-05. doi:10.14796/JWMM.R246-05.

James, R., K. Finney, N. Perera, W. James and N. Peyron. 2013. "SWMM5/PCSWMM Integrated 1D-2D Modeling." In Fifty Years of Watershed Modeling: Past, Present and Future, edited by A. S. Donigian, Jr and R. Field. ECI Symposium Series, P20. New York: Engineering Conferences International (ECI). http://dc.engconfintl.org/watershed/12.

Metzger, R. 2002. Modélisation des inondations par approaches déterministe et stochastique avec prise en compte des incertitudes topographiques pour la gestion des risqué lies aux crues. Lausanne: EPFL. Dissertation 2683.

Swisstopo. 2014. SwissAlti3d. Wabern, Bern: Federal Office of Topography swisstopo.

http://www.swisstopo.admin.ch/internet/swisstopo/en/ home/products/height/swissALTI3D.html.

USACE (U.S. Army Corps of Engineers). 2015. HEC-GeoRAS. Davis, CA: U.S. Army Corps of Engineers Hydrologic Engineering Center. http://www.hec.usace.army.mil/software/hec-georas/

Zanobetti, D. and H. Lorgeré. 1968. “Le modèle mathématique du delta du Mékong." La Houille Blanch, 1:17-30, 4:255-69 and 5:363-78. doi:10.1051//hb/1968002, doi:10.1051//hb/1968019, doi:10.1051/lhb/1968026. 